\title{
Assessment of Nurses' Knowledge toward Vascular Access Devices for Patients with Hemodialysis at Baghdad Teaching Hospital
}

\author{
Worood A. Mahmood, Msc. $\mathrm{N}^{1}$, Dr. Khalida M. Khudur, $\mathrm{PhD}^{2}$ \\ ${ }^{I}$ (Academic Nurse, Adults Nursing Department, College of Nursing, University of Baghdad, Iraq) \\ ${ }_{2}^{2}$ (Assistant Professor, Adults Nursing Department, College of Nursing, University of Baghdad, Iraq)
}

\begin{abstract}
As a result, increasing incidence of chronic kidney disease the use of vascular access devices has increase, but it still remains important to patients with chronic kidney disease to complete the process of hemodialysis fully.

Objective: the study objective is to assess nurse's knowledge toward vascular access devices and to find out the relationship between nurse's knowledge scores of the nurses and their selected demographic variable age, gender, marital status, level of education, years of experiences, and training sessions.

Methodology: A descriptive analytical study was conducted on a purposive "non-probability" sample of (80) nurses who have been working at hemodialysis units, were selected from Baghdad teaching hospitals which include Al-Yarmook teaching hospital, Baghdad Teaching Hospital, and Al-Kindy Teaching hospital, AlKarama Teaching Hospitals, Al-Kadhmiyia Teaching Hospitals, Surgical Specialties Hospitals. A questionnaire was used as a tool of data collection for the period of started fromOctober2 ${ }^{\text {nd }}, 2015$ through July $30^{\text {th }}, 2016$. Descriptive statistical analyses were used to analyze the data.

The data were collected through the use of constructed questionnaire, which consist of two parts; (1) Demographic data form that consist (7) items and (2) Nurses' knowledge that consist of (16) items, by means of direct interview technique. Reliability of the questionnaire was determined through a pilot study and the validity through a panel of (28) experts. Descriptive statistical analysis procedures (frequency, percentage, mean of score) and inferential statistical analysis procedures (Chi-square) were used for the data analysis.

Results: The results of the study indicated that (53.8\%) of the study sample were female, their advance age within 33-37 years, (70\%) were married and (50.0\%) were graduate from High institute graduate $(46.3 \%)$ had years of experience in hospital within (1-5) years and (62.2\%) had years of experience in hemodialysis units within (1-5) years, (66.3\%) don't sharing in training session.

Conclusions: The study indicated that there was significant relationship between (age, level of education, years of experiences in hemodialysis units, sharing in training session which established (by hospital, other institute inside or out Iraq) and nurses' knowledge toward vascular access devices.

Recommendations: The study recommended the special training session concerning vascular access devices in hemodialysis units. And booklets should be designed and presented to all hemodialysis nurses, in addition to make a new study that can assess nurses' knowledge concerning vascular access devices in hemodialysis units, the study recommended that the importance of employing Academic nurse in Hemodialysis units.
\end{abstract}

Keywords: Nurses' knowledge, Vascular Access Devices, Complication of VAD

\section{Introduction}

Hemodialysis is a transient treatment for those patients who are candidates for kidney transplantation and a permanent treatment for the end-stage renal disease patients with no chance of transplantation ${ }^{(1)}$.Hemodialysis needs vascular access sites with blood flow of at least $350 \mathrm{ml} / \mathrm{min}{ }^{(2)}$. Vascular Access to the patient's vascular system must be established to allow blood to be removed, cleansed, and returned to the patient's vascular system at rates between 200 and $800 \mathrm{~mL} /$ minute. Several types of access are available ${ }^{(3)}$.Without an appropriate vascular access, the quality of dialysis is reducing and its related morbidity and mortality increased ${ }^{(4)}$. The nurses play an important role in the therapeutic success and outcome of the patients because they minimize the patients risk factors for infections through maintaining strict aseptic technique, changing the (HD) Catheter dressing, inspecting the solution for signs of contamination. Monitoring the patients closely before, during, and after an exchange and recording his vital signs ${ }^{(5)}$.

\section{Methodology}

Descriptive study was carried out at hemodialysis units of Baghdad teaching hospitals to assess nurse's knowledge toward vascular access devices, study started from October $2^{\text {nd }}, 2015$ through July $30^{\text {th }}, 2016$. A purposive "non-probability"sample of (80) nurses, who have been working at hemodialysis units, were selected 
from Baghdad teaching hospitalswhich includeAl-Yarmook Teaching Hospital, Baghdad Teaching Hospital, and Al-KindyTeaching Hospital,Al-KaramaTeaching Hospital,Al-Kadhmiyia Teaching Hospital,Surgical Specialties Hospital.The data were collected in the period from $25^{\text {th }}$ February,2015 to $25^{\text {th }}$ April 2015.The researcher collected the samples by interview with nurses through a special designed questionnaire. This interview took a period of about 10-15 Minutes for each sample. The questionnaires was constructed and composed of two parts Part 1: Demographic Characteristics: It consists of (7) items which included: age, gender, marital status, level of education, Number of years in employment, Number of years in the hemodialysis units, number of training sessions, Part II: Nurses' knowledge toward vascular access deviceincludes (16) item toward complication of Vascular access devices which include (central venous device and arteriovenous fistula and arteriovenous graft).A pilot study was carried out between the periods from February $1^{\text {st }}, 2016$ to February $21^{\text {th }}, 2016$ on (10) nurses who work at hemodialysis units in Baghdad Teaching Hospitalto determine the reliability of the questionnaire and content validity was carried out through the 27 experts. Descriptive and inferential statistical measures were used to analyze the data.

\section{Results}

Table 1.Participants' Socio-demographicCharacteristics $(\mathrm{N}=80)$

\begin{tabular}{|c|c|c|}
\hline Variables & \multirow{2}{*}{ Frequency } & \multirow{2}{*}{ Percent } \\
\hline Age Groups (Years) & & \\
\hline $18-22$ & 1 & 1.3 \\
\hline $23-27$ & 18 & 22.5 \\
\hline $28-32$ & 22 & 27.5 \\
\hline $33-37$ & 27 & 33.8 \\
\hline $38-42$ & 8 & 10 \\
\hline 43 and more & 4 & 5.0 \\
\hline Gender & Frequency & Percent \\
\hline Male & 37 & 46.3 \\
\hline Female & 43 & 53.8 \\
\hline Marital Status & Frequency & Percent \\
\hline Single & 23 & 28.8 \\
\hline Married & 56 & 70 \\
\hline Widowed & 1 & 1.3 \\
\hline Educational Level & Frequency & Percent \\
\hline Primary nursing school graduate & 3 & 3.8 \\
\hline Secondary nursing school graduate & 16 & 20.0 \\
\hline High institute graduate & 40 & 50.0 \\
\hline Collage of nursing graduate & 7 & 8.8 \\
\hline College of science graduate & 14 & 17.5 \\
\hline Years of experience in hospitals & Frequency & Percent \\
\hline $1-5$ & 37 & 46.3 \\
\hline $6-10$ & 27 & 32.5 \\
\hline $11-15$ & 10 & 12.5 \\
\hline $16-20$ & 3 & 3.8 \\
\hline 21 and more & 4 & 5 \\
\hline Years of experience in hemodialysis & Frequency & Percent \\
\hline $1-5$ & 50 & 62.2 \\
\hline $6-10$ & 21 & 26.3 \\
\hline $11-15$ & 4 & 5 \\
\hline $16-20$ & 2 & 2.5 \\
\hline 21 and more & 3 & 3.8 \\
\hline Training Session & Frequency & Percent \\
\hline None & 53 & 66.3 \\
\hline 1 & 17 & 21.3 \\
\hline 2 & 3 & 3.8 \\
\hline 3 & 1 & 1.3 \\
\hline 4 & 4 & 5.0 \\
\hline 5 and more & 2 & 2.5 \\
\hline
\end{tabular}

Table (1)reveals that the majority of the sample were females $(43 \%)$ while $(37 \%)$ were male. According to their age; the highest percentage of the nurses (27\%) was within the age group (33-37) years. According to their marital status; the highest percentage of the nurses (56\%) was married. Regarding their education level; the highest percentages of the nurses $(40 \%)$ graduate from an institute. Concerning Years of employment; the highest percentage of the nurses (37\%) within the group (1-5) years. According to their Year of experience in hemodialysis; the highest percentage of the nurses (50\%) within the group (1-5) years, regarding theirtraining session; the highest percentage of the nurses (53\%) having no training session concerning vascular access devices. 
Table 2.Mean of Score of Nurses' Knowledge Toward Complication of Central Venous Devices for Patients' with Hemodialysis

\begin{tabular}{|c|l|c|c|c|c|c|}
\hline C1 & \multicolumn{1}{|c|}{ Items } & Yes & No & Uncertain & M.S & Ass \\
\hline 1 & Inadequate blood flow & 52 & 15 & 13 & 2.63 & Very good \\
\hline 2 & clotting under the subclavian & 22 & 32 & 26 & 1.86 & Fair \\
\hline 3 & Infection & 73 & 2 & 5 & 2.86 & Very good \\
\hline 4 & Pneumothorax & 5 & 55 & 20 & 1.41 & Fair \\
\hline 5 & *Edema & 54 & 13 & 13 & 1.53 & Fair \\
\hline 6 & Aneurysm* & 32 & 7 & 41 & 1.70 & Fair \\
\hline
\end{tabular}

Table (2) showsthat the mean of score for item of nurses' knowledge toward complication of central venous devices for patients' with hemodialysis was present the majority of nurses reflect a fair knowledge in items $(2,4,5,6)$ and the minority of nurses reflect a very good knowledge in items $(1,3)$.

Table 3.Mean of Score of Nurses' Knowledge Toward Complication of AVF and AVG for Patients' with Hemodialysis

\begin{tabular}{|c|l|c|c|c|c|c|}
\hline C2 & Items & Yes & No & Uncertain & M.S & Ass \\
\hline 1 & Edema & 57 & 7 & 16 & 2.64 & Very good \\
\hline 2 & Hematoma & 43 & 25 & 12 & 2.20 & Good \\
\hline 3 & Stenosis result from improper cannulation & 45 & 20 & 15 & 2.28 & Good \\
\hline 4 & Steal syndrome due to ischemia of the distal & 10 & 38 & 32 & 1.65 & Fair \\
\hline 5 & Congestive heart failure & 13 & 37 & 30 & 1.74 & Fair \\
\hline 6 & Central vein stenosis & 13 & 41 & 26 & 1.84 & Fair \\
\hline 7 & numbness and tingling in the extremity & 50 & 11 & 19 & 2.43 & Very good \\
\hline 8 & $*$ Clotting under the subclavian & 48 & 17 & 15 & 1.64 & Fair \\
\hline 9 & $*$ pneumothorax & 45 & 15 & 20 & 1.63 & Fair \\
\hline 10 & *Inadequate blood flow & 55 & 20 & 5 & 1.49 & Fair \\
\hline
\end{tabular}

Table (3) shows the mean of score for item of nurses' knowledge toward Complication of AVF and AVG for patients' with hemodialysis was present that the majority of nurses reflect fair knowledge in items $(4,5,6,8,9,10)$ and very good knowledge in items $(1,7)$ and good knowledge in item $(2,3)$.

Table 4.Association Between Nurses' Knowledge and Their Age Group (N=80)

\begin{tabular}{|l|c|c|c|}
\hline Age Groups & Fair & Good & TOTAL \\
\hline 18-22 years & & & \\
\hline $23-27$ years & 0 & 0 & 0 \\
\hline $28-32$ years & 7 & 7 & 19 \\
\hline $33-37$ years & 9 & 17 & 24 \\
\hline $38-42$ years & 0 & 4 & 27 \\
\hline $43 \leq$ year & 0 & 4 & 4 \\
\hline TOTAL & 28 & 52 & 80 \\
\hline$\chi^{2}$ obs. $=12.398 \quad d f=4$ & $\chi^{2}$ crit. $=9.488$, P-value $=0.01$ \\
\hline
\end{tabular}

Table (4) shows that there is a significant relationship between nurses' knowledge and their age group.

Table 5.Association Between Nurses' Knowledge and Their Gender (N=80)

\begin{tabular}{|l|c|c|c|}
\hline $\begin{array}{l}\text { Knowledge- } \\
\text { Gender }\end{array}$ & Fair & Good & Total \\
\hline Male & 12 & 25 & 37 \\
\hline Female & 15 & 28 & 43 \\
\hline Total & 27 & 53 & 80 \\
\hline$\chi^{2}$ obs. $=\mathbf{0 . 0 5 3} \quad$ df $=\mathbf{1}$ & $\chi^{2}$ crit. $=\mathbf{3 . 8 4}$ & \multicolumn{2}{|c|}{$\boldsymbol{P} \leq \mathbf{0 5}$} \\
\hline
\end{tabular}

$\chi^{2}$ Obs. $=$ Calculated Chi-Square, $\mathrm{df}=$ degree of freedom, $\mathrm{P}=$ probability, $\chi^{2}$ Crit. $=$ Tabulated Chi-square. Table (5) shows that there is no significant association between nurses' knowledge and their gender. 
Table 6.Association Between Nurses' Knowledge and Their Marital Status (N=80)

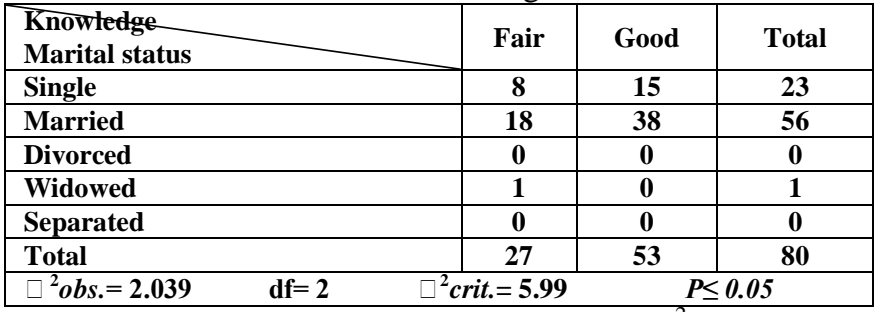

$\chi^{2}$ Obs. $=$ Calculated Chi-Square, $\mathrm{df}=$ degree of freedom, $\mathrm{P}=$ probability, $\chi^{2}$ Crit. $=$ Tabulated Chi-square

Table (6) shows that there is no significant association between nurses' knowledge and their marital.

Table 7.Association Between Nurses' Knowledge and Their Educational Level $(\mathrm{N}=80)$

\begin{tabular}{|l|c|c|c|}
\hline $\begin{array}{l}\text { Knowtedge } \\
\text { Education }\end{array}$ & Fair & Good & Total \\
\hline Primary nursing school & 2 & 1 & 3 \\
\hline Secondary nursing school & 11 & 5 & 16 \\
\hline High institute & 9 & 31 & 40 \\
\hline College of nursing & 0 & 7 & 7 \\
\hline College of science & 5 & 9 & 14 \\
\hline Total & 27 & 53 & 80 \\
\hline$\chi 2$ obs. $=16.07 \quad \mathrm{df}=4 \quad \chi 2$ crit. $=9.48$ & \multicolumn{2}{|c|}{ P-value $=0.003$} \\
\hline
\end{tabular}

$\chi^{2}$ Obs. $=$ Calculated Chi-Square, $\mathrm{df}=$ degree of freedom, $\mathrm{P}=$ probability, $\chi^{2}$ Crit. $=$ TabulatedChi-square

Table (7) shows that there is high significant association between nurses' knowledge and their educationallevel.

Table 8. Association Between Nurses' Knowledge and Their Years of Employment in Hospital (N=80)

\begin{tabular}{|l|c|c|c|}
\hline $\begin{array}{l}\text { Knowledge } \\
\text { Years }\end{array}$ & Fair & Good & Total \\
\hline $1-5$ & 15 & 22 & 37 \\
\hline $6-10$ & 8 & 18 & 26 \\
\hline $11-15$ & 3 & 7 & 10 \\
\hline $16-20$ & 0 & 3 & 3 \\
\hline $21 \leq$ & 1 & 3 & 4 \\
\hline Total & 27 & 53 & 80 \\
\hline$\chi^{2}$ obs. $=2.595 \quad \mathrm{df}=4$ & $\chi^{2}$ crit. $=4.48 \mathrm{P} \leq 0.05$ \\
\hline
\end{tabular}

$\chi^{2}$ Obs. $=$ Calculated Chi-Square, $\mathrm{df}=$ degree of freedom, $\mathrm{P}=$ probability, $\chi^{2}$ Crit $=$ Tabulated Chi-square

Table (8) shows that there is no significant association between nurses' knowledge and their years of employment in hospital.

Table 9.Association Between Nurses' Knowledge and Their Years of Employment in Hemodialysis Unit

\begin{tabular}{|l|c|c|c|}
\hline $\begin{array}{l}\text { Knowledge } \\
\text { Years }\end{array}$ & Fair & Good & Total \\
\hline $1-5$ & 26 & 24 & 50 \\
\hline $6-10$ & 1 & 20 & 21 \\
\hline $11-15$ & 0 & 4 & 4 \\
\hline $16-20$ & 0 & 2 & 2 \\
\hline $21 \square$ & 0 & 3 & 3 \\
\hline Total & 27 & 53 & $\mathbf{8 0}$ \\
\hline$\square^{2}$ obs. $=19.925 \quad d f=4$ & $\square^{2}$ crit. $=9.48$ P-value $=0.002$ \\
\hline
\end{tabular}

$\chi^{2}$ Obs. $=$ Observed Chi-Square, $\mathrm{df}=$ degree of freedom, $\mathrm{P}=$ probability, $\chi^{2}$ Crit. $=$ Chi-Square critical

Table (9) showed that there ishigh significant association between nurses' knowledge and their years of employment in hemodialysis unit.

Table 10.Association Between Nurses' Knowledge and Their participation in training courses $(\mathrm{N}=8)$

\begin{tabular}{|l|c|c|c|}
\hline $\begin{array}{l}\text { Knowtedge } \\
\text { Participation }\end{array}$ & Fair & Good & Total \\
\hline Yes & 4 & 23 & 27 \\
\hline No & 23 & 30 & 53 \\
\hline Total & 27 & 53 & 80 \\
\hline$\chi^{2}$ obs. $=6.535 \quad \mathrm{df}=1 \quad \chi^{2}$ crit. $=3.84$ & \multicolumn{2}{|c|}{ P-value $=0.01$} \\
\hline
\end{tabular}

$\chi^{2}$ Obs. $=$ CalculatedChi-Square, $\mathrm{df}=$ degree of freedom, $\mathrm{P}=$ probability, $\chi 2$ Crit. $=$ Tabulated Chi-square.

Table (10) shows that there is a significant association between nurses' knowledge and their participation in training courses. 


\section{Discussion}

Discussion of the Socio-demographic Characteristics of Studied Sample (Table 1):

Through the data analysis of distribution of the socio-demographic variables, (Table 1)reveals that approximately half of the study sample (53.8\%) were females. this result agrees with Bakey (2008) who showed that the majority of $(51 \%)$ of nurse staff in hemodialysis were female ${ }^{(6)}$, but this result disagrees with Bakey (2012) who showed in a study which was conducted in hemodialysis at Baghdad teaching hospitals that the majority of the study sample $(53.3 \% \%)$ were Male ${ }^{(7)}$.

The highest proportion (33.8\%) of the sample are within the age group (33-37) years old. This finding agree with a study done byPhilip (2016), who showed that the majority of (53.3\%) in experimental group and $(43.3 \%)$ in control group of the staff nurses was (26-35) years old ${ }^{(8)}$. Buttheresult disagrees with a study done byBakey (2008), who indicate that $(43.1 \%)$ of them was (26-30) years old ${ }^{(6)}$.

In regard to marital status, the majority $(70 \%)$ of the sample were married. Concerning the level of education, most of them (50\%) were nursing institute graduates, this result agrees with Bakey (2008) who showed that the majority (56.9\%) of nurses were married and the level of education, most of them $(40.4 \%)$ were nursing institute graduate ${ }^{(6)}$. But this result disagrees with the study which was conducted to investigate knowledge of and practices toward universal precautions among health care workers and medical students in 2 university hospitals in Mazandaran Povine, Islamic Republic of Iran, showed that the majority $(64.3 \%)$ had bachelor degree in nursing ${ }^{(9)}$.

Regarding years of experiences in hospitals, more than half of the study sample had (1-5) experiences years in hospitals that represented (46.3\%). This result agrees with Bakey (2008) who showed that the majority of years of experiences in hospitals for nurses was $(51.1 \%)^{(6)}$, but the result disagree with the study was conducted to investigate knowledge of and practices toward universal precautions among health care workers and medical students in 2 university hospitals in Mazandaran Povine, Islamic Republic of Iran, shoes that the majority $(40.6 \%)$ of the nurse staff had $(0-5)$ years of experience in hospitals ${ }^{(9)}$.

Regardingyears of experiences in hemodialysis, most of them than had (1-5) experiences years in hemodialysis units that represented (62.5\%). And this finding comes in agreement with Bakey (2008) who reported that the majority of nurse staff had $(56.9 \%)$ years of experience in hemodialysis units ${ }^{(6)}$. But this result disagrees with (Nihmatolla, et al., 2005) reported that (82.5\%) of nurses had (1-3) years of experiences in hemodialysis and peritoneal dialysis units ${ }^{(10)}$.

The finding indicated that more than half of the study sample (66.3\%) had no opportunity to be involved in training session concerning vascular access devices which established by the hospitals, the result agrees with Bakey (2008) who reported that the majority of nurse staff had (64.7\%) had no opportunity to be involved in training session concerning hemodialysis which established by the hospitals. ${ }^{(6)}$.

\section{Discussion of nurses' knowledge toward complication of central venous devices for patients' with hemodialysis:}

Table(2) showed that the mean of score for item of nurses' knowledge toward complication of central venous devices for patients' with hemodialysis was present the majority of nurses reflect a Fair knowledge in items $(2,4,5,6))$ the minority of nurses reflect very good knowledge in items $(1,3)$. Based on the researchers' point of view, these finding mean that nurses who work in $\mathrm{HD}$ had fair level of knowledge concerningcomplication of central venous devices for all HD staff and needed to develop their knowledge to be up -to data of any knowledge related to vascular access devices.

This result supported by Jeong, et al., 2013 Showed in a study that the Complications associated with CVC use are known to increase patient morbidity and mortality, as well as increase medical treatment costs and length of stay ${ }^{(11)}$.

Also, O'Grady, et al., 2011 show that the Central venous catheters (CVCs) are commonly used for vascular access in patients who require hemodialysis; CVC use is associated with bloodstream infections (BSI) because of skin breaks during insertion ${ }^{(12)}$.

\section{Discussion of nurses' knowledge toward complication of AVF and AVG devices for patients' with hemodialysis:}

This tables (3) showed the mean of score for item of nurses' knowledge toward Complication of AVF and AVG for patients' with hemodialysis was present that the majority of nurses reflect fair knowledge in items $(4,5,6,8,9,10)$ and very good knowledge in items $(1,7)$ and good knowledge in items $(2,3)$.

Based on the researcher 's point of view, these finding mean that nurses who work in HD had fair level of knowledge concerningcomplication of AVF and AVG and all HD staff nurses needed to develop their knowledge to be up-to-date of any knowledge related to vascular access device. 
This results supported by Ikizler, et al.,2006 show in their study that the complication of AVF include thrombosis, infection, bleeding, increased venous pressure, arterial insufficiency, aneurysm, carpal tunnel syndrome, distal ischemia and even heart failure ${ }^{(13)}$.

Also; Ghonemy, et al., 2016 show in his finding that the stenosis of the vascular access was the most common complication as it occurred in about $53 \%$ of the patients. Infection of the vascular access was the second common complication as it occurred in more than $50 \%$ of the patients. The incidence of Systemic infection occurred in $22 \%$ of the patients. Stenosis may have occurred partly due to excessive in-growth of fibrous tissue through multiple puncture holes, and partly due to repeated attacks of hypotension during and after the hemodialysis ${ }^{(14)}$

\section{Discussion of Association Between Association between nurse's knowledge and their demographic characteristic Data (Tables 4-10):}

Age:The data analysis of Table (4) shows that that was a significant relationship at p -value (0.01) level between nurses' knowledge and their age, this result agrees with the study which was done by Bakey (2008) who present that there was significant relationship between nurses' knowledge and their age ${ }^{(6)}$.This result disagrees with study conducted by Paul (2007) who represents that there was no significant relationship between nurse's knowledge and their age ${ }^{(15)}$

Gender:Table (5) indicates shows that there was no significant relationship at p- value $(\leq 0.05)$ level between nurse's knowledgeand their genderThis finding agree with Bakey (2008) showed that there was no significant relationship between nurse's knowledge and their age ${ }^{(6)}$.

Marital Status:Table (6) revealed that there was no significant relationship at p- value $(\leq 0.05)$ level between nurse's knowledge and their marital status.This result agrees with the study which was done by Bakey (2008) who present that there was no significant relationship between nurses' knowledge and their marital status ${ }^{(6) .}$ This result disagrees with the study which was done by Bakey (2012) who present that there was significant relationship between nurses' nurses' practice and their marital status ${ }^{(7)}$.

Level of education: Table (7) revealed that there was a significant relationship at $p$-value (0.003) level between nurse's knowledge and their level of education.This result agrees with the study which was done by Bakey (2008) who present that there was significant relationship between nurses' knowledge and their education level ${ }^{(6)}$.This result disagrees with the study which was done by Bakey (2012) who present that there was no significant relationship between nurses' practice and their education level ${ }^{(7)}$.

Years of experiences in hospitals:Table (8) indicates that there was no significant relationship at $\mathrm{p}-\mathrm{value}(\leq$ 0.05)level between nurse's knowledge and years of experiences in hospitalsThis result agrees with the study which was done by Bakey (2008) who present that there was no significant relationship between nurses' knowledge and years of experiences in hospitals ${ }^{(6)}$.

Years of experiences in HD units: Table (9) showed that there is high significant relationship at $\mathrm{p}$-value (0.002)level between nurse's knowledge and years of experiences in HD units. This result agrees with the study which was done by Bakey (2008) who present that there was significant relationship between nurses' knowledge and years of experiences in HD units ${ }^{(6)}$. this result disagrees with the study which was done by Bakey (2012) who present that there was no significant relationship between nurses' practice and years of experience in HD ${ }^{(7)}$.

Training session: The results presented in table (10) reveals that there It shows that there was significant relationship at $\mathrm{p}$-value(0.01)level between nurse's knowledge and their sharing in training session. This result agrees with the study which was done by Bakey (2008) who present that there was significant relationship between nurses' knowledge and years their sharing in training session in hospital ${ }^{(7)}$.

\section{Conclusion}

The study indicated that there was significant relationship between (age, level of education, years of experiences in hemodialysis units, sharing in training session which established (by hospital, other institute inside or out Iraq) and nurses' knowledge toward vascular access devices.

\section{Recommendations}

The study recommended the special training session concerning vascular access devices in hemodialysis units. Also, booklets should be designed and presented to all hemodialysis nurses, in addition to 
make a new study that can assess nurses' knowledge concerning vascular access devices in hemodialysis units, the study recommended that the importance of employing Academic nurse in Hemodialysis units.

\section{References}

[1]. Gilpin V, Nichols WK. Vascular access for hemodialysis: Thrills and thrombosis. J Vasc Nurs. 2010; 28:78-83. [PubMed].

[2]. Chhetri PK, Manandhar DN, Lamichhane S. Vascular access for hemodialysis in Nepal medical college and Teaching hospital. Nepal Med Coll J. 2009; 11:111-4. [PubMed].

[3]. Smeltzer, S.; Bara.; Hinkle, J.; Cheever, K.; Brunner and Suddarth's Text Book of Medical Surgical Nursing, $2^{\text {nd }}$ edition, 2010, Lippincott Williams and Wilkins Company, U.S., P. 1926.

[4]. Vanholder R. Vascular access: Care and monitoring of function. Nephrol Dial Transplant. 2001; 16:1542-5. [PubMed].

[5]. Zabat, E.: When your patients need peritoneal Dialysis. Nursing,2003, Vol 33, NO .8, pp. 52-53.

[6]. Bakey, Serwan Jafar. Assessment of Nurses' knowledge toward Hepatitis B Virus in Hemodialysis Unit. (Thesis) University of Baghdad, College of Nursing, 2008.pp .105 -106-113-114-115.

[7]. Bakey, Serwan Jafar. Evaluation of Nurses' Practices Throughout Hemodialysis Treatment for Patients in Hemodialysis Unit at Baghdad Teaching Hospitals. (Thesis) University of Baghdad, College of Nursing, 2012.

[8]. Philip,L.L., A Study to Assess the Effectiveness of Structured Teaching Program on Knowledge Regarding Prevention of Infection among the Staff Nurses Working in Hemodialysis unit in Selected Hospitals in Chhattisgarh state, India. International Journal ofScience and Research (IJSR), Vol5 Issue 2, 2016, P.272.

[9]. Motamed, N.; Baba Mahmoodi, F; Khalilian, A.; Peykanheirati, M. and Nozari, M.: Knowledge and practices of healthcare worker and medical students towards universal precautions in hospitals in Mazandaran province, WHO: Eastern Mediterranean Health Journal, September, 2006, Vol. 12, No.., 5.

[10]. Nihmatolla, R; Al-Barzengi, H and Al-Gersha, k: Assessment of infection Control Process at Hemodialysis and Peritoneal Dialysis units in Kurdistan Region. (Thesis) university of Hawler, College of Nursing ,2005.

[11]. Jeong, I. S., Park, S. M., Lee, J. M., Song, J. Y., \& Lee, S. J. (2013). Effect of central line bundle on central line-associated bloodstream infections in intensive care units. American journal of infection control,41(8), 710- 716. doi: 10.1016/j.ajic.2012.10.010

[12]. O'Grady NP, Alexander M, Burns LA, Dellinger EP, Garland J, Heard SO, et al. Summary of recommendations: Guidelines for the Prevention of Intravascular Catheter-related Infections. Clin Infect Dis. 2011;52(9):1087-99.

[13]. Ikizler TA, Himmerlfarb J. Trials and tradeoffs in hemodialysis vascular access monitoring. Nephrol Dial Transplant.2006; $21: 3362$.

[14]. Ghonemy, T. A, Farag, S. E, Soliman S, A, Amin, E .M, Zidan, A.A.Vascular access complications and risk factors in hemodialysis patients: A single center study. Alexandria Journal of Medicine;(2016); Vol. (52), N0 (1): $\mathrm{P}_{\mathrm{P} .}$ 68-70.

[15]. Paul, p.: Nurses ' knowledge of their Legal Responsibilities towards patients Care, The Nursing Journal of INDIA, 2007, Vol. XCVIII, No.9. 